\title{
Differential Role for BiP3 in Rice Immune Receptor-Mediated Resistance
}

\author{
Chi-Yeol Kim $\cdot$ Muho Han $\cdot$ Chang-Jin Park $\cdot$ Jong-Seong Jeon
}

Received: 11 June 2014 / Accepted: 4 July 2014 / Published Online: 31 August 2014

(C) The Korean Society for Applied Biological Chemistry and Springer 2014

\begin{abstract}
Endoplasmic reticulum-bound chaperone luminalbinding protein 3 (BiP3) has been found to regulate the immunity mediated by the membrane-bound extracellular immune receptors $X a 3 / X a 26$ and $X a 21$, that encode non-arginine-aspartate (non-RD) kinases, against the bacterial pathogen Xanthomonas oryzae pathovar oryzae (Xoo). In contrast, BiP3 appeared not to regulate the immunity mediated by the intracellular immune receptor Pi5, which encodes a nucleotide-binding domain and leucine-rich repeat (NB-LRR) protein, against the fungal pathogen Magnaporthe oryzae. To further examine this differential role for BiP3 in rice immunity, we generated transgenic rice plants overexpressing BiP3 in the background of the NB-LRR intracellular immune receptor Xal that confers resistance to Xoo. Our molecular genetic and phenotype analyses revealed that $B i P 3$ overexpression does not affect Xal-mediated rice resistance to Xoo. Our current results thus provide evidence that $B i P 3$ regulates membrane-bound nonRD kinase-mediated, but not the intracellular NB-LRR-mediated, rice immune responses and that its function does not depend on the type of pathogen.
\end{abstract}

Keywords endoplasmic reticulum-bound chaperone luminalbinding protein $3 \cdot$ nucleotide-binding domain and leucine-rich repeat $\cdot X a 1 \cdot$ Xanthomonas oryzae pathovar oryzae

\section{Introduction}

Plants sense a wide range of microbes via immune receptors that

C.-Y. Kim and M. Han contributed equally.

C.-Y. Kim · M. Han · J.S. Jeon $(\triangle)$

Graduate School of Biotechnology \& Crop Biotech Institute, Kyung Hee

University, Yongin 446-701, Republic of Korea

E-mail: jjeon@khu.ac.kr

C.-J. Park

Department of Bioresources Engineering, Sejong University, Seoul 143 747 , Republic of Korea monitor extracellular or intracellular spaces for microbe-associated molecules (Jones and Dangl, 2006; Boller and Felix, 2009). Based on the currently available data, the cell surface recognition of pathogen-specific molecules is mediated by membrane-bound immune receptors such as $\mathrm{Xa} 3 / \mathrm{Xa} 26$ and $\mathrm{Xa} 21$, which are a nonarginine-aspartate (non-RD) class of kinases (Song et al., 1995; Sun et al., 2004; Dardick and Ronald, 2006). Plants also contain intracellular immune receptors, which are mostly nucleotide binding-leucine rich repeat (NB-LRR) proteins. The NB-LRR proteins are characterized by a tripartite domain architecture consisting of an N-terminal coiled-coil or Toll/interleukin-1 receptor domain, a central NB domain, and a C-terminal LRR domain (Martin et al., 2003; Liu et al., 2007).

Membrane-bound immune receptors are synthesized in the endoplasmic reticulum (ER), where they are subjected to a quality control process responsible for monitoring the correct folding and processing of membrane and secretory proteins ( $\mathrm{Li}$ et al., 2009; Nekrasov et al., 2009; Park et al., 2010; Saijo, 2010). Recently the ER-bound HSP70 luminal-binding protein (BiP) was found to be one of the main chaperones regulating the biogenesis and degradation of membrane-bound immune receptors. For example, the Xa21mediated immune response is compromised in $B i P 3$-overexpressing rice plants due to a reduced stability of Xa21 upon Xanthomonas oryzae pathovar oryzae (Xoo) inoculation (Park et al., 2010). BiP3 overexpression also compromises the resistance mediated by rice Xa3/Xa26 upon Xoo inoculation (Park et al., 2014).

In contrast, $B i P 3$ overexpression does not affect Pi5-mediated resistance in rice to the fungal pathogen Magnaporthe oryzae, indicating that overexpressed $\mathrm{BiP} 3$ does not have a role in the biogenesis of Pi5 itself or in Pi5-mediated signaling (Park et al., 2014). However, many Arabidopsis NB-LRR proteins are found to localize at the ER, suggesting that they may require ER chaperones for maturation (Caplan et al., 2009; Padmanabhan and Dinesh-Kumar, 2010). These previous findings prompted us to examine if the differential effects of overexpressed BiP3 on the rice immune responses to Xoo mediated by the non-RD kinases $\mathrm{Xa3} / \mathrm{Xa} 26$ and Xa21 and to $M$. oryzae mediated by the Pi5 encoded NB-LRR are due to different classes of immune receptor 
or different species of pathogen. To address this question, in the present study we generated and analyzed transgenic rice plants overexpressing BiP3 in a background containing the NB-LRR immune receptor $\mathrm{Xal}$ that confers resistance to Xoo.

\section{Materials and Methods}

Plant materials and growth conditions. The rice cultivar (cv.) Kitaake and monogenic resistance line IRBB1 carrying Xal (Yoshimura et al., 1998) were used as susceptible and resistance control lines, respectively. All rice plants were grown in a greenhouse at $30^{\circ} \mathrm{C}$ during the day and at $20^{\circ} \mathrm{C}$ at night with a light/dark cycle of $14 / 10 \mathrm{~h}$ for inoculation and seed harvesting.

Production of transgenic rice lines. We generated $\mathrm{BiP3}$ overexpressing lines in an IRBB1 background by introducing the BiP3-OX vector carrying maize Ubiquitin promoter:BiP3 fusion using Agrobacterium-mediated transformation (Park et al., 2010). DNA extraction and genotypic analysis. Independent transgenic plants were verified by genomic DNA polymerase chain reaction (PCR) analysis. Total genomic DNAs were extracted from the young leaves of seedlings following the method of Chen and Ronald (1999). PCR amplification was performed in a final volume of $40 \mu \mathrm{L}$ (100 pmol of each primer, $20 \mu \mathrm{M}$ dNTPs, 10 $\mathrm{mM}$ Tris- $\mathrm{HCl} \mathrm{pH} 9.0,2 \mathrm{mM} \mathrm{MgCl} 2,50 \mathrm{mM} \mathrm{KCl}, 0.1 \%$ Triton $\mathrm{X}$ 100 , and $0.5 \mathrm{U}$ Taq polymerase) using $50 \mathrm{ng}$ of genomic DNA as template. The amplification conditions were as follows: $94^{\circ} \mathrm{C}$ for $5 \mathrm{~min}$ followed by 35 cycles of $94^{\circ} \mathrm{C}, 1 \mathrm{~min} ; 56^{\circ} \mathrm{C}, 1 \mathrm{~min}$; and $72^{\circ} \mathrm{C}, 1 \mathrm{~min}$, with a final extension at $72^{\circ} \mathrm{C}$ for $5 \mathrm{~min}$. The PCR primers used were as follows: $\mathrm{BiP} 3,5^{\prime}$-GCTGCTGCTATTGCGT ACGGTTTGGACA-3' and 5'-AATCATCGCAAGACCGGCAA CAGG-3'; Xal, 5'-ACTGCCCTCTTGCACACGCCTTTGG-3' and 5'-CTGCCAACTGAATTACCAGTTGCA-3'.

RNA preparation and reverse transcription polymerase chain reaction (RT-PCR) analysis. To examine the expression of BiP3 in the leaves of $B i P 3-O X$ lines, total RNA was prepared using Trizol reagent (Invitrogen, USA) with DNase treatment (TURBO DNA-free kit; Ambion-Life technologies, USA). First-strand cDNAs were amplified with RT-PCR reactions using BiP3-specific primers. OsUBQ5 was amplified as an RT-PCR control using the primers, 5'-GACTACAACATCCAGAAGGAGTC-3' and 5'-TC ATCTAATAACCAGTTCGATTTC-3'. PCR amplifications were performed as described by Han et al. (2013).

Pathogen inoculation and disease evaluation. The Xoo strain KXO85 (Korean race 1), a causal agent of bacterial blight in rice, was used. KXO85 is incompatible with the IRBB1 background. KXO85 was grown on Peptone Sucrose Agar (PSA; peptone 10, sucrose 10, agar 16, glutamate $1 \mathrm{~g} / \mathrm{L}, \mathrm{pH} 7.5$ ) plates with cephalexin $(15 \mathrm{mg} / \mathrm{L})$ at $28^{\circ} \mathrm{C}$. Fully expanded flag-leaves of each tiller from 10-week-old plants were inoculated with a Xoo suspension $\left(\mathrm{OD}_{600}=0.8\right)$ using the scissors-dip method as described by Han et al. (2013). Lesion lengths were measured from the cut surface at the tip to the distal-most position on the leaf that exhibited a grey
(A)

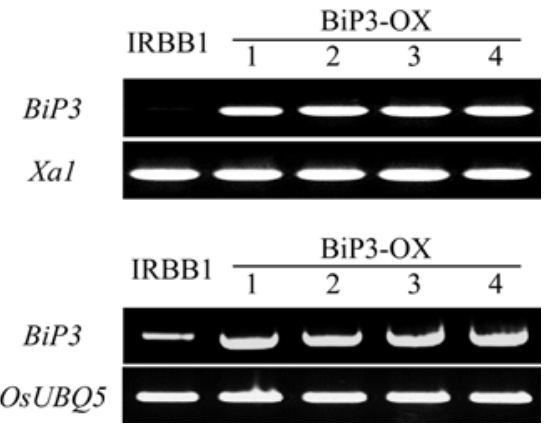

Fig. 1 Molecular characterization of IRBB1 rice plants carrying Xal and $B i P 3$-overexpressing transgenes (BiP3-OX transgenic lines). (A) Genomic DNA PCR analysis of $X a 1$ and $B i P 3$ genes from the IRBB1 and $\mathrm{T}_{0}$ transgenic BiP3-OX lines. (B) RT-PCR analysis of BiP3. Control RT-PCR was carried out using $O s U B Q 5$ specific primers.

chlorotic lesion at different intervals after pathogen inoculation. To determine the size of the bacterial populations, three inoculated leaves from each genotype were ground and resuspended in 10 $\mathrm{mL} \mathrm{H}_{2} \mathrm{O}$ to separately harvest bacteria. Diluted extracts were then plated on PSA media containing $15 \mathrm{mg} / \mathrm{L}$ cephalexin.

\section{Results and Discussion}

Four transgenic rice plants overexpressing $\mathrm{BiP} 3$ in a background containing the NB-LRR immune receptor $\mathrm{Xal}$ were generated and the presence of the BiP3-OX transgene in each plant was examined by genomic DNA PCR (Fig. 1A). The expression levels of $B i P 3$ in the leaves of transgenic plants were monitored by RTPCR. BiP3 expression was found to be highly increased in four independent BiP3-OX lines compared to the control IRBB1 line (Fig. 1B). No morphological changes were observed in these transgenic plants compared to the control plants.

To verify whether overexpressed BiP3 affects Xal-mediated immunity to Xoo, two BiP3-OX lines (BiP3-OX1 and BiP3-OX2) were challenged with this pathogen at 10 weeks of age. The IRBB1 line exhibited high resistance to Xoo and showed very short lesions of approximately $0.3-0.5 \mathrm{~cm}$ following exposure to the incompatible Xoo strain KXO85. Transgenic plants overexpressing $B i P 3$ displayed resistance to $X o o$ with short lesions similar to the IRBB1 control, demonstrating that BiP3 overexpression does not have an effect on Xal-mediated resistance. Kitaake is a Xoo susceptible rice cultivar (Yoshimura et al., 1998) and in our current experiment exhibited long lesions of approximately 15-17 $\mathrm{cm}$ (Figs. 2A and B). The bacterial population measurements also correlated well with lesion length development i.e. a much smaller Xoo population was detected in BiP3-OX and IRBB1 plants compared with the susceptible Kitaake control plants (Fig. 2C). These results indicated that overexpression of BiP3 does not compromise Xal-mediated resistance to Xoo in rice.

It is now hypothesized that $\mathrm{BiP} 3$ is required for the proper 
(A)

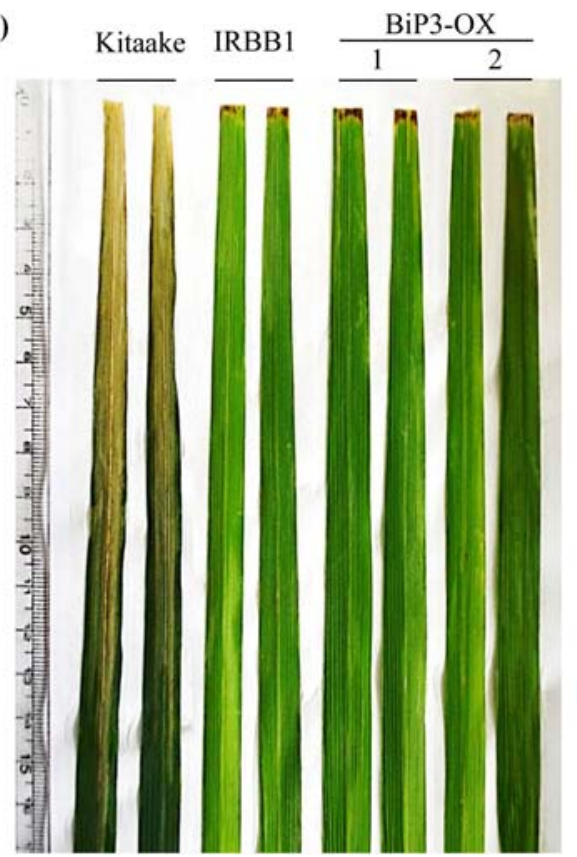

(B)
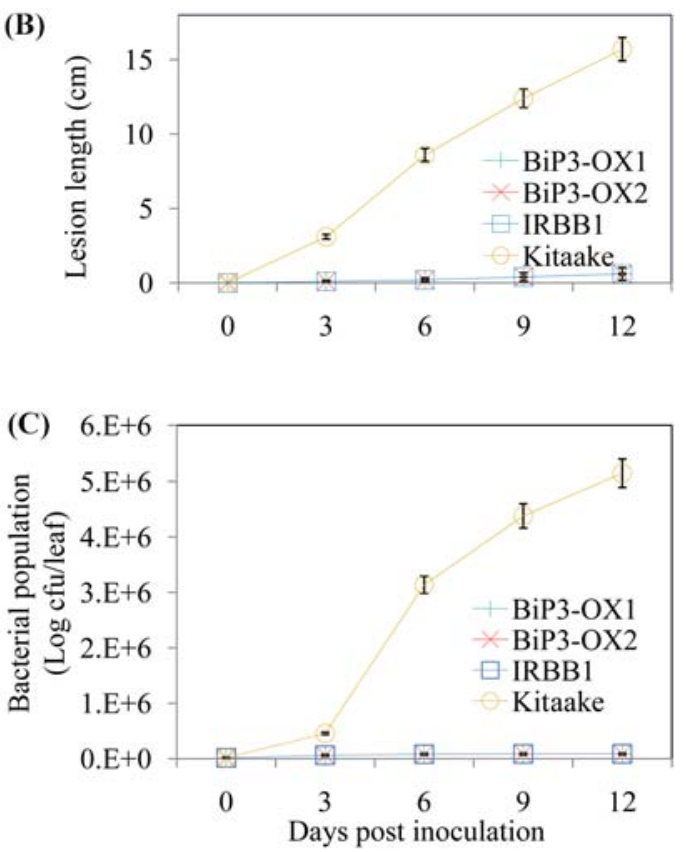

Fig. 2 Disease phenotype analysis of BiP3-OX transgenic plants. (A) Water-soaked lesions on the leaves of Kitaake plants (a susceptible control), IRBB1 (resistant control plants), and BiP3-OX lines. The pictures were taken 12 days after inoculation of these lines with Xoo strain KXO85. (B) Leaf lesion lengths of BiP3-OX transgenic and control lines after Xoo inoculation of the flag leaves of 10-week-old plants. For each time point, the lesion length was determined separately for three leaves at a similar growth stage from three plants. Each bar represents the average and standard deviation of three leaves. (C) Bacterial population sizes in BiP3-OX transgenic and control lines. For each time point, the bacterial population size was determined separately for three leaves at a similar growth stage from three plants. Error bars represent the standard deviation of three leaves.

folding and maturation of membrane-bound non-RD kinase immune receptors, such as $\mathrm{Xa} 3 / \mathrm{Xa} 26$ and $\mathrm{Xa} 21$, which pass through the ER during their biogenesis. It is thus likely that the correct folding of the extracellular domain of these immune receptors undergoes quality control in the ER, which would be a critical step in plant immune response pathways. The overexpression of BiP3 likely perturbs this ER quality control, resulting in incorrect folding of $\mathrm{Xa3} / \mathrm{Xa} 26$ and Xa21 and impaired resistance to Xoo.

In summary, we have here found that the overexpression of $B i P 3$ in rice does not affect Xal-mediated resistance to Xoo. Our results clearly reveal a differential requirement of $B i P 3$ in rice immune responses to Xoo mediated by the non-RD kinases Xa3/ $\mathrm{Xa} 26$ and Xa21 and by the NB-LRR Xa1 protein product. This indicates that the differential requirement of $B i P 3$ in rice immunity is not caused by the type of pathogen, but by the type of immune receptor that is involved in the response. Our results provide evidence that $B i P 3$ regulates the membrane-bound non-RD kinase-mediated immunity but not immune responses mediated by intracellular NB-LRR protein in rice.

Acknowledgments This work was supported by grants from the NextGeneration BioGreen 21 Program, Rural Development Administration (PJ008156012013), and from the Mid-Career Researcher Program, National Research Foundation (NRF-2013R1A2A2A01068887).

\section{References}

Boller T and Felix G (2009) A renaissance of elicitors: perception of microbeassociated molecular patterns and danger signals by pattern-recognition receptors. Annu Rev Plant Biol 60, 379-406.

Caplan JL, Zhu X, Mamillapalli P, Marathe R, Anandalakshmi R, and DineshKumar SP (2009) Induced ER chaperones regulate a receptor-like kinase to mediate antiviral innate immune response in plants. Cell Host Microbe 6, 457-69.

Chen DH and Ronald PC (1999) A rapid DNA minipreparation method suitable for AFLP and other PCR applications. Plant Mol Biol Rep 17, 53-7.

Dardick C and Ronald PC (2006) Plant and animal pathogen recognition receptors signal through non-RD kinases. PLoS Pathog 2, e2.

Han M, Ryu HS, Kim CY, Park DS, Ahn YK, and Jeon JS (2013) OsWRKY30 is a transcription activator that enhances rice resistance to the Xanthomonas oryzae pathovar oryzae. J Plant Biol 56, 258-65.

Jones JD and Dangl JL (2006) The plant immune system. Nature 444, 323-9.

Li J, Zhao-Hui C, Batoux M, Nekrasov V, Roux M, Chinchilla D et al. (2009) Specific ER quality control components required for biogenesis of the plant innate immune receptor EFR. Proc Natl Acad Sci USA 106, 15973-8.

Liu J, Liu X, Dai L, and Wang GL (2007) Recent progress in elucidating the structure, function and evolution of disease resistance genes in plants. $J$ Genet Genomics 34, 765-76.

Martin GB, Bogdanove AJ, and Sessa G (2003) Understanding the functions of plant disease resistance proteins. Аппи Rev Plant Biol 54, $23-61$.

Nekrasov V, Li J, Batoux M, Chu ZH, Lacombe S, Rougon A et al. (2009) Control of the pattern-recognition receptor EFR by and ER protein 
complex in plant immunity. EMBO $J \mathbf{2 8}, 3428-38$.

Padmanabhan MS and Dinesh-Kumar SP (2010) All hands on deck-the role of chloroplasts, endoplasmic reticulum, and the nucleus in driving plant innate immunity. Molecular Plant-Microbe Interactions 23, 1368-80.

Park CJ, Bart R, Chern M, Canlas PE, Bai W, and Ronald PC (2010) Overexpression of the endoplasmic reticulum chaperone $B i P 3$ regulates XA21-mediated innate immunity in rice. PLoS One 5, e9262.

Park CJ, Song MY, Kim CY, Jeon JS, and Ronald PC (2014) Rice BiP3 regulates immunity mediated by the PRRs XA3 and XA21 but not immunity mediated by the NB-LRR protein, Pi5. Biochem Biophys Res Commun 448, 70-5.
Saijo Y (2010) ER quality control of immune receptors and regulators in plants. Cell Microbiol 12, 716-24.

Song W, Wang G, Chen L, Kim H, Pi L, Holsten T et al (1995) A receptor kinase-like protein encoded by the rice disease resistance gene, Xa21. Science 270, 1804-6.

Sun X, Cao Y, Yang Z, Xu C, Li X, Wang S et al. (2004) Xa26, a gene conferring resistance to Xanthomonas oryzae pv. oryzae in rice, encodes an LRR receptor kinase-like protein. Plant J 37, 517-27.

Yoshimura S, Yamanouchi U, Katayose Y, Toki S, Wang ZX, Kono I et al. (1998) Expression of Xal, a bacterial blight-resistance gene in rice, is induced by bacterial inoculation. Proc Natl Acad Sci USA 95, 1663-8. 